Удк 37.018.43:004

DOI: https://doi.org/10.35387/od.2(16).2019.20-28

Базелюк Олександр Васильович - кандидат педагогічних наук, докторант Інституту професійно-технічної освіти НАПН України

ORCID iD https://orcid.org/0000-0002-3206-2287

E-mail: o.bazeliuk@ukr.net

\title{
ВИБІР І ВИКОРИСТАННЯ ЦИФРОВИХ ЗАСОБІВ В ОСВІТНЬОМУ ПРОЦЕСІ ЗАКЛАДІВ ПРОФЕСІЙНОЇ (ПРОФЕСІЙНО-ТЕХНІЧНОЇ) ОСВІТИ
}

Анотація. У статmі проаналізовано проблему використання цифррових засобів в освітньому процесі закладів профресійної (профресійнотехнічноі) освіти. Автор виходить з того, що цифррові технології $i$ засоби надають нові освітні можливості педагогічним працівникам закладів профресійної освіти, але водночас спонукають до пошуку нових підходів до реалізації завдань освітнього прочесу, що неможливо здійснити без високого рівня володіння цифровими засобами та розвитку власної цифрованої компетентності і культури. У процесі дослідження було визначено, що цифрова культура педагогічного працівника закладу профресійної освіти $\epsilon$ інтегральним френоменом, прояви якого можна знайти у кожному з компонентів професійної компетентності.

У статті зосереджено особливу увагу на проблемі визначення рівня використання цифрових технологій у освітньому процесі закладів профресійної освіти. Автор доходить висновку, що їі доцільно вирішувати із урахуванням SAMR-моделі P. Пуентедура, яка складається із чотирьох висхідних рівнів від заміни/імітації реальних засобів до рівня створення завдань, що не мають відповідників у реальному світі. Окремо наголошено на тому, що саме відсутність аналогів у реальному світі стає найбільшою складністю у процесі розвитку цифрової культури особистості педагогічного працівника закладу профресійної освіти. 3 огляду на те, що кількість цифрових засобів і додатків безперервно зростає, то для їх коректного і обгрунтованого вибору автор пропонує використовувати «Падагогічне колесо» А. Керрінгтона, яке створене на основі таксономії освітньої сфери Б. Блума та з урахуванням SAMRмоделі. Однак, «Падагогічне колесо», на думку автора, $\epsilon$ допоміжним інформаційно-довідковим засобом, а не цілісною методичною системою.

Ключові слова: профресійна освіта, цифровізація освіти, цифрова культура, цифрові засоби, педагогічні працівники.

Bazeliuk Oleksandr - Candidate of Pedagogical Sciences, Doctor Student at the Institute of Vocational Education and Training of the NAES of Ukraine

ORCID iD https://orcid.org/0000-0002-3206-2287

E-mail: o.bazeliuk@ukr.net 


\title{
SELECTION AND USE OF DIGITAL TOOLS IN THE EDUCATION PROCESS OF VOCATIONAL EDUCATIONAL AND TRAINING INSTITUTIONS
}

\begin{abstract}
In the article the author discusses the problem of using digital tools in the education process of vocational educational and training institutions. The author assumes that digital technologies and tools provide VET institutions teachers with new educational opportunities, but at the same time encourage teachers to search for new approaches to implement education process tasks that cannot be achieved without a high level of digital tools mastering and developing their own digital competence and culture.

It was defined during the study that VET institution teacher's digital culture is an integral phenomenon, which can be found in each of the professional competency components.

The article focuses on the problem of defining the level of digital technologies usage in the VET institutions education process. The author concludes that this problem should be solved taking into account $R$. Puentedura's SAMR model, which consists of four ascending levels from substitution to redefinition, creation of new tasks, previously inconceivable. It is emphasized that the biggest difficulty in the process of VET institution teacher's digital culture development becomes the absence of analogues in the real world.
\end{abstract}

The number of digital tools and applications is constantly growing, so the author proposes to use A. Carrington's "The Padagogy Wheel", which was created to on the basis of B. Bloom's Taxonomy of Educational Objectives. and the SAMR model for their correct and reasonable selection. However, the Padagogy Wheel, according to the author, is an auxiliary information reference tool, not a holistic methodological system.

Key words: vocational education, education digitalization, digital culture, digital tools, teachers.

Постановка проблеми. В останні роки до наукового обігу стрімко увійшло поняття цифрової культури , яке стає показником сформованості цифрової компетентності, цифрової грамотності та невід'ємною частиною сучасного інфрормаційного суспільства У педагогічній науці сформованість цифрової культури, разом із показниками цифрової компетентності та цифрової грамотності , стає своєрідним індикатором високого рівня профресійної підготовки сучасно го педагога. Стрімкий розвиток цифрових засобів і технологій створює для педагогічної спільноти нові можливості і нові проблеми. Сучасний освітній процес уже важко уявити без доступу до мережі Інтернет, що є основою цифрових технологій (Биков, 2011; Морзе еt al., 2019, Базелюк et al., 2018). Уже звичним $є$ використання смартфонів, планшетів, ноутбуків для вирішення різноманітних та різнопланових освітніх задач і завдань.

Фокус розробників цифрових технологій зараз зосереджений на 
двох основних напрямах, а саме:

- розвиток персональної електроніки (саме персональної, а не просто мобільних електронних пристроїв);

- розвиток цифрових сервісів, які об'єднують широкий спектр пристроїв та програмних засобів у єдину віртуальну систему.

Відповідно до означених напрямів, зростаюча кількість цифрових засобів, сервісів та додатків, що з'являються майже щоденно ускладнюють педагогам створення відповідних дидактичних матеріалів та необхідного для їх використання методичної забезпечення.

Mema cmammi - здійснити науковий аналіз та запропонувати шляхи вирішення проблеми вибору та використання цифрових засобів в освітньому процесі закладів професійної (професійно-технічної) освіти.

Аналіз останніх досліджень i публікацій. Методологічні і концептуальні засади професійної освіти та освіти дорослих висвітлено у працях С. Гончаренка, Р.Гуревича, М. Копельчака, Л. Лук'янової, Н. Ничкало, В. Радкевич та ін.. Концептуальним засадам інформатизації та цифровізації освіти присвячені роботи В. Бикова, А. Гуржія, С. Литвинової, Н. Морзе та ін.. Висвітлення широкого спектра проблем використання сучасних електронних засобів у освітньому процесі професійної освіти здійснено в роботах О. Спіріна, А. Каленського, М.Пригодія та ін.. Методологічні аспекти дистанційного професійного навчання розкриті в низці робіт Л. Петренко, С. Кравець та ін.. Використання електронних освітніх ресурсів та створення SMART-комплексів для професійної освіти розкривається в роботах О. Гуменного, А. Кононенка, Л. Липської та ін.. Водночас, залишається недослідженою проблема обґрунтування вибору та структурування цифрових засобів педагогічними працівниками закладів професійної (професійно-технічної) освіти для конкретних ситуацій або занять освітнього процесу.

Виклад основного матеріалу дослідження. Із розвитком технічного прогресу глобальний і, відповідно, вітчизняний ринки праці мають зрослі потреби у висококваліфікованих робітниках, що робить їх ринками інтелектуальної робочої сили, здатними задовольнити потреби економіки у прискореному інноваційному розвитку. Активізація знаннєвого чинника спричинена, зокрема, посиленням ринкової конкуренції та, як наслідок, потребою у постійному процесі запровадження інновацій, що, по суті, є втіленням нових ідей персоналу на базі нових знань та інформації (Радкевич, 2012).

У свою чергу, запровадження цифрових інновацій на даному технологічному етапі у глобалізованому суспільстві вимагає від педагогічного працівника закладу професійної (професійно-технічної) освіти високого рівня володіння цифровими засобами та технологіями, які необхідно постійно удосконалювати та розвивати. Цю думку, у контексті досліджень присвячених проблемам андрагогіки, підтримує і Л. Лук'янова, яка, відзначає характерні чинники сучасного цифрового освітнього простору, а саме: усвідомлення власної причетності кожної людини до 
світової спільноти з її культурними загальними і професійними тенденціями як результат процесу глобалізації; динамікою процесів і явищ навколишнього середовища, які необхідно усвідомлювати, сприймати, адаптуватись до них; суттєвими кількісними й змістовими змінами інформаційного простору, що потребують умінь самостійно здобувати й переопрацьовувати інформацію, переносити і використовувати її в нових, змінених умовах (Лук'янова, 2012).

Як відомо, цифрові технології забезпечують удосконалення освітнього процесу, дають змогу автоматизувати контроль і оцінювання навчальної успішності студентів, організовувати ефективну комунікацію студентів і викладачів, обмін досвідом, сприяють розвитку творчих здібностей студентів (Радкевич et al., 2018). Відповідно, успішне використання цифрових засобів і технологій у освітньому процесі залежить, насамперед, від розвитку цифрової культури педагогічних працівників закладів професійної (професійно-технічної) освіти.

Структура професійної компетентності викладача професійної освіти, яка була запропонована авторами, представлена такими компонентами: інформаційний (критичне мислення), інноваційний (креативність), особистісний (комунікації), практично-діяльнісний (спільна робота). (Радкевич et al., 2018, с. 10) 3 огляду на таку структуру цифрова культура педагогічних працівників закладів професійної освіти визначатиметься як інтегральний феномен, прояви якого можна знайти у кожному з означених компонентів.

Підкреслимо, що для цифрового світу важливим стає особистіснотворчий (креативний) компонент, що характеризує специфічні якості його особистості та здатність до ефективної і продуктивної взаємодії 3 суб'єктами й об'єктами цифрового середовища, спрямовані на їх пізнання та творче перетворення. Однак реалізація його тісно пов'язана із рівнем використання цифрових технологій у освітньому процесі закладів професійної освіти. Для вирішення означеної проблеми С. Литвинова пропонує застосовувати модель SAMR (Substitution, Augmentation, Modification, Redefinition), розроблену вченим Р. Пуентедура (Ruben Puentedura) (Литвинова, 2019; Puentedura, 2019). Дана модель складається з чотирьох висхідних рівнів.

Перший рівень - підміна (Substitution). Технології використовуються без внесення функціональних змін у процеси. С. Литвинова пояснює, що на даному рівні IT використовуються для виконання тих самих дії, що і раніше. Наприклад: друк тексту замість написання, заміна приладів комп'ютерними моделями або електронне тестування замість паперового. Другий рівень - накопичення (Augmentation). На цьому рівні технології вносять функціональні зміни у процес. У інтерпретації С. Литвинової - IT стає ефективним інструментом для виконання індивідуальних завдань, накопичення власного досвіду використання IT в освітніх цілях.

Третій рівень - модифікація (Modification). Технології дозволяють 
здійснити значний (significant) редизайн завдань. На цьому рівні IT використовуються для спільного виконання навчальних завдань або освітнього проекту.

Четвертий рівень - перетворення (Redefinition). Технології дозволяють створювати нові завдання, раніше неможливі. С. Литвинова пояснює, що це - співпраця у команді, е-обмін даними. Наприклад, OneNote або Sway в Office 365, або виконання міні-проекту з природничоматематичних предметів. Учасники команди співпрацюють, для виконання конкретного завдання або вирішення проблеми; отримують зовнішню підтримку, інформацію або дані.

Таким чином, на основі аналізу запропонованих рівнів варто відзначити, що цифровими стають електронні засоби, які використовуються педагогічним працівником закладу професійної освіти на третьому та четвертому рівнях, оскільки вимагають значних змін у формуванні завдань та урахуванні нових, які досі не зустрічались, можливостей цифрових сервісів, які не мають аналогів у традиційній дидактиці та відповідників у реальному світі. Втім, найбільша практична складність для будь-якого педагога у цифровізованому освітньому процесі полягає не лише у тому, що постає необхідність розуміти характерні особливості змін, які відбуваються в освіті під впливом процесів цифрової трансформації, скільки у коректному і обґрунтованому виборі цифрових засобів для навчання. Це особливо складно з огляду на те, що процеси появи і зникнення цифрових засобів і сервісів $€$ нормою для сучасного цифрового простору. Також важливо зважати і на кількість цифрових засобів. Наприклад, 18 вересня 2019 року за результатами 13-го щорічного опитування інструментів для навчання (Annual Learning Tools Survey) Дж. Хард (Jane Hart) представила рейтинг «Топ 200 інструментів для навчання 2019» (The Top 200 Tools for Learning 2019, 2019), який включає 200 цифрових сервісів і додатків. Одним зі шляхів вирішення цього складного завдання стало запропоноване А. Керрінгтоном «Падагогічне колесо» (рис. 1), яке було розроблене з урахуванням SAMR та на основі таксономії освітньої ссрери Б. Блума. А. Керрінгтон запропонував класифрікувати програмне забезпечення (у четвертій версії 126 цифрових сервісів та додатків, а у 5-й вже 188) за двома тріадами когнітивних навичок, а саме:

- навички мислення нижчого рівня (Lower order thinking skills), які інкапсулюються у такій послідовності: запам'ятовування (remembering) розуміння (understanding) - застосування (applying);

- навички мислення високого рівня (Higher order thinking skills), які розкриваються і такій послідовності: аналіз (analyzing) - оцінювання (evaluating) - створення (creating). 


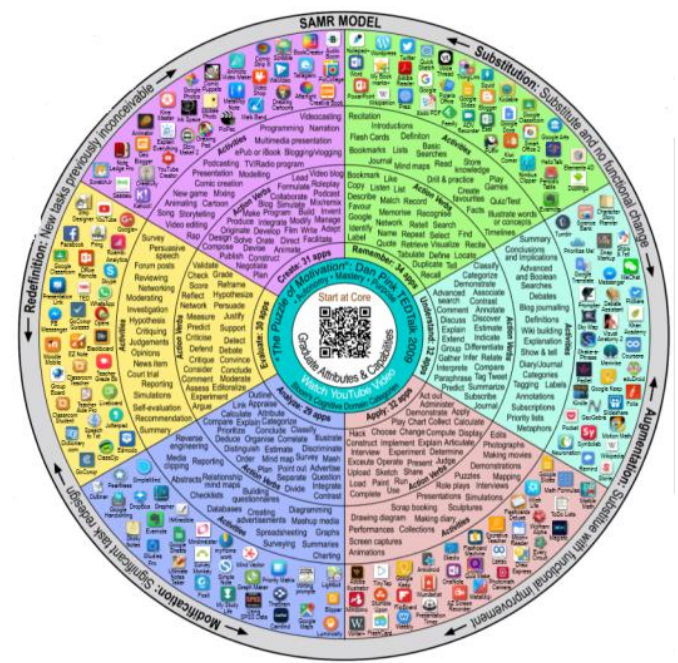

Рис. 1. «Падагогічне колесо» А. Керрінгтона (Carrington, 2016)

Кожна навичка мислення має перелік дієслів, що позначають дію в межах конкретної когнітивної навички. Наприклад, для «Запам'ятовування» (remember) позначені такі дієслова дії (action verbs) як: знаходити, вподобати, додати в обране, загуглити тощо. Крім того, запропоновані «Форми роботи» (activities). Наприклад, для сектору «Розуміння» (understanding) такими є: дебати, резюме, ведення блогу тощо. У свою чергу до кожного блоку форм роботи запропонований цифровий сервіс або програмний засіб. Наприклад, для сектору «Розуміння» запропоновані: Evernote, Twitter, Debate Champ, Story Planner тощо.

Такий підхід дозволив структурувати великий обсяг видів освітньої діяльності, форм роботи, а головне систематизувати величезну кількість програмних додатків та цифрових сервісів, і значно спростити педагогу їхній вибір у конкретній педагогічній ситуації.

Втім, не варто абсолютизувати запропоновану систему класифікації цифрових сервісів та додатків для освіти. Оскільки вона має ряд суттєвих недоліків. По-перше - можливості цифрових сервісів і додатків значно ширші і часто виникає запитання: чому додаток віднесений до однієї категорії, а не до іншої (чи не представлений у декількох). Подруге, запропонований розподіл форм роботи не завжди відповідає характеру конкретної діяльності і сам розподіл, часто, не є однозначним. Наприклад, така форма роботи як «Ведення блогу» віднесений до сегменту «Розуміння», хоча може бути віднесений і до сегменту «Застосування».

Крім того, запропоновані А. Керрінгтоном критерії відбору цифрових сервісів та додатків до «Педагогічного колеса» часто 
відсортовують програми буквально, наприклад до сектору «Оцінювання» (evaluate) віднесено цифровий сервіс (соціальну мережу) Facebook, що на думку автора відповідає дієсловам дії: перевіряти (check), експериментувати (experiment), оцінювати (assess).

3 огляду на зазначене вище, вважаємо, що «Падагогічне колесо» А. Керрінгтона доцільно розглядати як допоміжний інформаційнодовідковий засіб, а не як цілісну методичну систему.

Висновки та перспективи подальших досліджень. Таким чином, цифрові технології і засоби надають нові освітні можливості педагогічним працівникам закладів професійної освіти, але водночас спонукають до пошуку нових підходів до реалізації завдань освітнього процесу, що неможливо здійснити без високого рівня володіння цифровими засобами та розвитку власної цифрованої компетентності і культури. Значна кількість цифрових сервісів і додатків стає певним стримувальним чинником у цьому процесі.

Цифрова культура педагогічного працівника закладу професійної освіти є складовою його професійної компетентності і позначається як інтегральний феномен, прояви якого можна знайти у кожному 3 їі компонентів.

Визначення рівня використання цифрових технологій у освітньому процесі закладів професійної освіти доцільно здійснювати з урахуванням SAMR-моделі, яка складається із чотирьох висхідних рівнів від заміни/імітації реальних засобів до рівня створення завдань, що не мають відповідників у реальному світі. Саме відсутність аналогів у реальному світі стає найбільшою складністю у процесі розвитку цифрової культури особистості педагогічного працівника закладу професійної освіти.

3 огляду на те, що кількість цифрових засобів та додатків безперервно зростає, для їх коректного і обґрунтованого вибору можна використовувати «Падагогічне колесо» А. Керрінгтона, яке створене на основі таксономії освітньої сфери Б. Блума та з урахуванням SAMRмоделі. Утім, «Падагогічне колесо» $є$ допоміжним інформаційно-довідковим засобом, а не цілісною методичною системою.

Водночас невирішеними залишаються питання загальної організації цифровізованого освітнього процесу закладів професійної (професійно-технічної) освіти, забезпечення безпеки його учасників у віртуальному цифровому просторі. Також потребують розкриття різні аспекти розвитку цифрової культури педагогічних працівників закладів професійної (професійно-технічної) освіти у контексті глобалізованого цифрового простору.

\section{Список використаних джерел}

Базелюк, О. В., Спірін, О. М., Петренко, Л. М., $\quad$ Каленський, А. А., $\quad$ \& Майборода, Л. А. (2018). Технології дистанційного професійного навчання. Житомир: Полісся.

Биков, В. Ю. (2011). Технології хмарних обчислень, ІКТ-аутсорсінг та нові 
функції ІКТ-підрозділів навчальних закладів і наукових установ. Інформаційні технології в освіті, 10, 8-23.

Литвинова, С. Г. (2019). Моделі впровадження і оцінювання ефективності системи комп'ютерного моделювання як інноваційної освітньої ІКтехнології. Фізико-математична освіта, 2(20), 80-88. https://doi.org/10.31110/2413-1571-2019-020-2-013

Лук'янова, Л. Б. (2012). Розвиток освіти дорослих в Україні: вимоги часу. In В.Г. Кремень et al. (Eds) Педагогічна і психологічна науки в Україні. Т. 4 Неперервна професійна освіта: теорія і практика (сc. 414-423). Київ: Педагогічна думка.

Морзе, Н., Вембер, В., \& Бойко, М. (2019). Використання цифрових технологій для формувального оцінювання. Відкрите освітнє есередовище сучасного університету, (Спецвипуск), 202-214. https://doi.org/10.28925/2414-0325.2019s19

Радкевич, В. (2012). Проблеми професійного навчання кваліфікованих робітників для потреб інноваційної економіки. Науковий вісник Інституту профресійно-технічної освіти НАПН України. Профресійна педагогіка, (3), 5-10. https://doi.org/10.32835/2223-5752.2012.3.5-10

Радкевич, В., Романова, Г., \& Бородієнко, О. (2018). Концептуальні основи практико-орієнтованої підготовки викладачів професійної освіти і навчання. Науковий вісник Інституту професійно-технічної освіти НАПН України. Профресійна педагогіка, (16), 5-13. https://doi.org/10.32835/2223-5752.2018.16.5-13.

Carrington, A. (2016, September 3). The Padagogy Wheel. English V5. URL: https://designingoutcomes.com/assets/PadWheelV5/PW_ENG_V5.0_ Android_SCREEN.pdf

Puentedura, R. (2019). Navigating Change: SAMR and the EdTech Quintet. Presentation. URL: http://hippasus.com/rrpweblog/archives/2019/02/ NavigatingChange_SAMRAndTheEdTechQuintet.pdf

Top 200 Tools for Learning 2019. (2019). Results of the 13th Annual Learning Tools.

Survey published 18 September $2019 . \quad$ URL: https://www.toptools4learning.com/

\section{References (translated and transliterated)}

Bazeliuk, O. V., Spirin, O. M., Petrenko, L. M., Kalenskyi, A. A., \& Maiboroda, L. A. (2018). Technologies of Distance Professional Learning. Zhytomyr: Polissia. (In Ukrainian)

Bykov, V. Yu. (2011). Cloud Computing Technologies, ICT Outsourcing and New Functions of Education Institutions and Research Establishments ICT Divisions. Informatsiini tekhnolohii v osviti, (10), 8-23. (In Ukrainian)

Lytvynova, S. (2019). Models of Implementation and Evaluation of the Efficiency of a Computer Modelling System as an Innovative Educational IC-Technology. Physical and Mathematical Education, 2(20), 80-88. https://doi.org/10.31110/2413-1571-2019-020-2-013 (In Ukrainian)

Lukianova, L. B. (2012). Adult Education Development in Ukraine: Time 
Requirements. In V. H. Kremen et al. (Eds) Pedahohichna i psykholohichna nauky $v$ Ukraini. Vol. 4 Neperervna profesiina osvita: teoriia i praktyka (pp. 414-423). Kyiv: Pedahohichna dumka. (In Ukrainian)

Morze, N., Vember, V., \& Boiko, M. (2019). Using Digital Technologies for Formative Assessment. Open Educational e-Environment of Modern University, (Special Edition), 202-214. https://doi.org/10.28925/2414-0325.2019s19 (In Ukrainian)

Radkevych, V. (2012). Problems of Skilled Workers' Vocational Training for the Needs of Innovation Economy. Scientific Herald of the Institute of Vocational Education and Training of NAES of Ukraine. Vocational Pedagogy, (3), 5-10. https://doi.org/10.32835/2223-5752.2012.3.5-10 (in Ukrainian)

Radkevych, V., Romanova, G., \& Borodiyenko, O. (2018). Conceptual Foundations of Future VET Teacher's Training. Scientific Herald of the Institute of Vocational Education and Training of NAES of Ukraine. Vocational Pedagogy, (16), 5-13. https://doi.org/10.32835/2223-5752.2018.16.5-13. (in Ukrainian)

Carrington, A. (2016, September 3). The Padagogy Wheel. English V5. Retrieved from:

https://designingoutcomes.com/assets/PadWheelV5/PW_ENG_V5.0_Andr oid_SCREEN.pdf (in English)

Puentedura, R. (2019). Navigating Change: SAMR and the EdTech Quintet. Presentation,

http://hippasus.com/rrpweblog/archives/2019/02/NavigatingChange_SAMR AndTheEdTechQuintet.pdf (in English)

Top 200 Tools for Learning 2019. (2019). Results of the 13th Annual Learning Tools Survey published 18 September 2019.2 URL: https://www.toptools4learning.com/ (in English)

\section{удк 347.7}

DOI: https://doi.org/10.35387/od.2(16).2019.28-38

Vasylenko Olena - Candidate of Pedagogical Sciences, Associate Professor, Professor of the Foreign Languages Department of the National Academy of Internal Affairs

ORCID ID: https://orcid.org/0000-0002-6364-7317

E-mail: olena-vasylenko@ukr.net

\section{GLOBAL TRENDS OF ADULT EDUCATION IN THE UNESCO'S DOCUMENTS}

Abstract. The article is devoted to the problem of global trends and directions of development in adult learning and education that are considered in UNESCO's documents. It is noted that UNESCO, as a specialized agency of the United Nations, promotes international cooperation in education, science and culture, its priorities include the achievement of quality education for all and lifelong learning, as well as the creation of an inclusive knowledge-based 